\title{
ESTUDOS POTENCIOMETRICOS DE SOLUÇŌES AQUOSAS DE FERRO (II) E FERRO (III) EM PRESENÇA DE BÓRAX E SILICATO DE SÓDIO
}

Paulo Cỉcero do Nascimento e Denise Bohrer do Nascimento

Departamento de Quỉmica. Centro de Ciências Naturais e Exatas. UFSM. Santa Maria, RS.

Iduvirges Lourdes Müller

Departamento de Metalurgia. Programa de Pós-Graduação em Engenharia Metalúrgica e dos Materiais. UFRGS. Porto Alegre, RS.

RESUMO

Determinou-se a variação do potencial num eletrodo de pla tina brilhante imerso em soluções de Ferro (II) e Ferro (III) adi cionadas de bórax e silicato de sódio. Tanto o börax quanto o sili cato mostraram taxas altas de variação de potencial apenas no siste $\mathrm{maFe}{ }^{+2} / \mathrm{Pt}(\Delta \mathrm{E} / \Delta \mathrm{V}=82 \mathrm{mv} / \mathrm{ml}$ para börax - Ferro (II) e $\Delta E / \Delta \mathrm{V}=20$ $\mathrm{mv} / \mathrm{ml}$ para silicato - Ferro (II). Para o sistema $\mathrm{Fe}^{+3} / \mathrm{Pt}$ as taxas foram idênticas para börax e silicato e muito baixas $(\Delta E / \Delta V=2 m v / m l)$. SUMMARY

NASCIMENTO, P.C.; NASCIMENTO, D.B., and MÜLLER, I.L., 1987 . Poten tiometric studies of Iron (II) and Iron (III) in aqueons solutions with borax and sodium silicate. Ciência e Natu $r a, 9: 33-36,1987$.

Potentiometric studies in borax $\mid \mathrm{Fe}^{+2}-\mathrm{Fe}^{+3}-\mathrm{Pt}$ and sodium silicate $\mid \mathrm{Fe}^{+2}-\mathrm{Fe}^{+3}-\mathrm{Pt}$ solutions were done. It is observed, by means of potencial variations a high affinity of borax and sodium silicate with $\mathrm{Fe}^{+2}$ and a poor affinity with $\mathrm{Fe}^{+3}$

INTRODUÇÃO

0 bōrax e o silicato de sōdio são bons inibidores da cor rosão do aço carbono devido, em parte, ao pH elevado de suas soluções (que estabiliza o filme de óxido protetor formado sobre o metal) e, em parte, devido à incorporação de boro e de silīicio (na forma de $\mathrm{SiO}_{2}$ ) ao filme com a formação de compostos estáveis que podem dimi nuir a dissolução do metal. Sendo assim, torna-se importante identi ficar alguma interação entre as espécies que formam os produtos de corrosão do aço carbono [Ferro (II) e Ferro (III)] e as espécies que podem inibi-la (bórax e silicato de sódio).

PARTE EXPERIMENTAL

Foram realizadas medidas do potencial das soluções aquosas àcidas de cloreto férrico e cloreto ferroso $(0,01 \mathrm{M})$ sobre eletrodo da platina brilhante na presença de börax $(0,01 \mathrm{M})$ e silicato de só dio xaporoso $\left(0,01 \mathrm{M}\right.$ em relação a $\left.\mathrm{SiO}_{2}\right)$. Todos os potenciais referem-se 


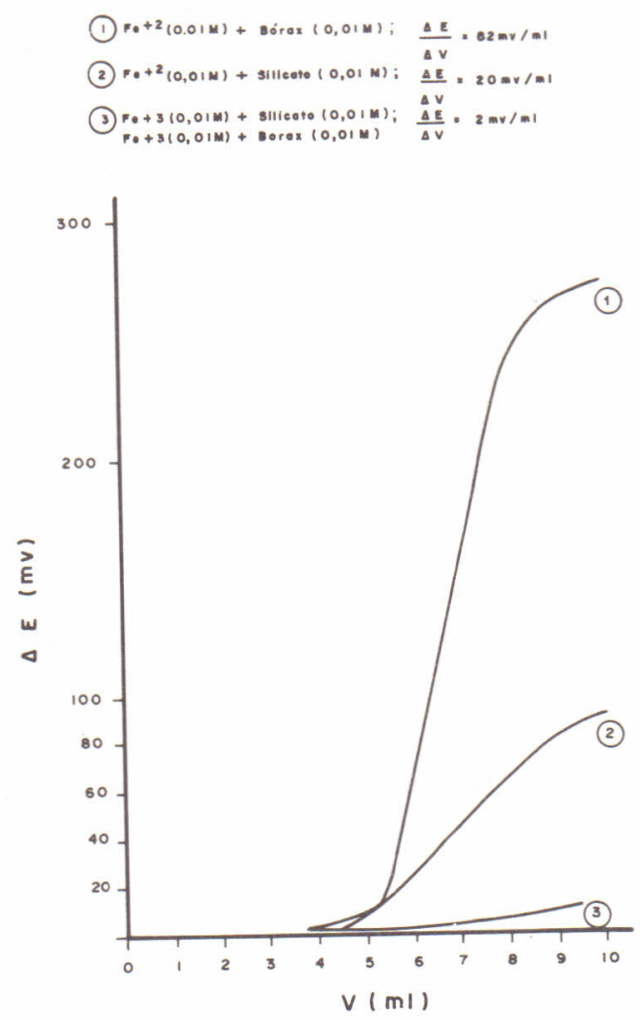

Figura 1 - Gräfico de $\Delta E(m v) \times \operatorname{Vadc}(m l)$ de bōrax e silicato de sō dio em soluções de Ferro (II) e Ferro (III).

\begin{tabular}{|c|c|}
\hline $\mathrm{Fe}^{+2}+\mathrm{V}(\mathrm{m})$ & ) $B O R A X$ \\
\hline$V(m 1)$ & $\Delta E(m V)$ \\
\hline 4,4 & 0,8 \\
\hline 6,0 & 73.9 \\
\hline 6,5 & 115,2 \\
\hline 7,0 & 156,1 \\
\hline 7,5 & 196,5 \\
\hline 8,0 & 238,3 \\
\hline $\begin{array}{l}\text { Coeficiente } \\
\text { caa linear }= \\
\text { (exceto } 10 \\
\text { Declividade }\end{array}$ & $\begin{array}{l}\text { Correla- } \\
0.999 \\
\text { onto) } \\
=82,06\end{array}$ \\
\hline
\end{tabular}

\begin{tabular}{|cc|}
\hline $\mathrm{Fe}^{+2}+V(\mathrm{~m} 1)$ & DE SILICATO DE SODIO \\
\hline$V(\mathrm{~m} 1)$ & $\Delta E(\mathrm{mV})$ \\
\hline 3,6 & 0,9 \\
\hline 5,5 & 13,6 \\
\hline 6,0 & 24,5 \\
\hline 6,5 & 34,3 \\
\hline 7,0 & 43,8 \\
\hline 7,5 & 54,3 \\
\hline 8,0 & 63,9 \\
\hline 8,5 & 74,3 \\
\hline
\end{tabular}

\begin{tabular}{|cr|}
\hline $\mathrm{Fe}^{+3}+V(m 1)$ & BORAX \\
\hline$V(m 1)$ & $\Delta E(m V)$ \\
\hline 6,2 & 1,2 \\
\hline 7,0 & 1,7 \\
\hline 7,5 & 2,8 \\
\hline 8,0 & 3,4 \\
\hline 8,5 & 4,8 \\
\hline 9,0 & 5,9 \\
\hline 9,5 & 6,7 \\
\hline
\end{tabular}

\begin{tabular}{|cc|}
\hline $\mathrm{Fe}^{+3}+\mathrm{V}(\mathrm{m} 1)$ & SILICATO DE SODIO \\
\hline$V(\mathrm{~m} 1)$ & $\Delta E(\mathrm{~m} V)$ \\
\hline 3,5 & 1,5 \\
\hline 7,0 & 1,8 \\
\hline 7,5 & 2,7 \\
\hline 8,0 & 3,3 \\
\hline 8,5 & 5,0 \\
\hline 9,0 & 5,7 \\
\hline 9,5 & 6,7 \\
\hline
\end{tabular}
$\begin{array}{ll}\text { Coeficiente Correla- } & \text { Coeficiente Correlação Linear } \\ \text { cáo Linear }=0,996 & =0,993 \text { (exceto } 10 \text { Ponto) } \\ \text { lexcetto } 10 \text { ponto) } & \text { Decilividade }=2,01\end{array}$

Coeficiente Correlação Linear $=0,998$ Declividade $=2,04$ Declividade $=20,05$

Figura 2 - Valores de variação de potencial em soluções de Ferro(II) e Ferro (III) na presença de börax e silicato de sódio. 
ao eletrodo de colomelano saturado (ECS) e o sistema montado consis tia de uma célula convencional para dois eletrodos com aberturas que permitiam o desarejamento contīnuo da solução através da passagem de $\mathrm{N}_{2}$ segundo o método de GILROY e MAYNE (1). A temperatura foi man tida em $18,0+0,5^{\circ} \mathrm{C}$ e no preparo das soluções usou-se somente āgua bidestilada. O pH do meio foi mantido em torno de 2,5 a partir da adição de $\mathrm{H}_{2} \mathrm{SO}_{4} 1,0 \mathrm{~N}$ e as medidas realizadas sem parar a agitação ou interromper o fluxo de $\mathrm{N}_{2}$. A quantidade de silicato de sódio xa roposo necessāria à produção de uma solução $0,01 \mathrm{M}$ em Sio 2 foi cal culada a partir da anālise química realizada no silicato xaroposo comercial. A adição de bōrax ou silicato de sōdio ao sistema, só iniciava apōs o desarejamento $(\sim 1$ hora) garantir um potencial estāvel.

\section{ANĀL ISE DO SILICATO}

As soluções de silicato foram analisadas em relação ao teor de silica $\left(\mathrm{SiO}_{2}\right)$ gravimetricamente (2) a partir da desidrata ção com ácido clorídrico. Neste método o silicato é convertido em ăcido silícico pela adição de ācido clorỉdrico concentrado. 0 sóli do obtido do aquecimento da solução rica em ácido silücico é adicio nado de āgua bidestilada, aquecido à ebulição e posteriormente fil trado em papel de filtração lenta. O precipitado retido pelo filtro é calcinado em mufla elétrica à $1000{ }^{\circ} \mathrm{C}$ e a massa de resíduo obtida corresponde à quantidade de sỉlica $\left(\mathrm{SiO}_{2}\right)$ contida no volume da solu ção analisada.

\section{RESULTADOS E DISCUSSÃO}

As variações de potencial encontradas a partir da adição de bōrax ou silicato de sōdio às soluções de Ferro (II) e Ferro (III) podem ser observadas nas figuras (1) e (2). Verifica-se uma grande variação no potencial por "ml" de bōrax e silicato adicionados às soluções de Ferro (II) devido provavelmente a formação de algum si 1 icato ferroso (3) no caso do sistema silicato de sódio-ferro (II) Pt e de algum composto entre Ferro (II) e espécies derivadas de bō rax, talvez o complexo $\mathrm{Fe}\left[\mathrm{B}(\mathrm{OH})_{4}\right]^{+}$sugerido por SEO et alii (4) ou a espécie $\mathrm{Fe}\left(\mathrm{B}_{4} \mathrm{O}_{7}\right)_{n}^{2-2 n}$ sugerida por OGURA (5).

0 bórax é de um modo geral mais eficaz na inibição da cor rosão do aço carbono do que o silicato de sōdio (6) e isto pode ser atribuïdo em parte a maior afinidade existente entre Ferro (II) (que é um dos produtos iniciais de corrosãol e as espécies presentes em solução derivadas do bórax.

CONCLUSOTES

Tanto o bōrax quanto o silicato de sōdio mostraram taxas altas de variação de potencial somente no sistema $\mathrm{Fe}^{+2}-\mathrm{Pt}$. Isto 
pode sugerir algum tipo de interação preferencial entre $\mathrm{Fe}^{+2} \mathrm{e}$ as espécies que contēm boro e $\mathrm{SiO}_{2}$, talvez uma de reação complexa ção, como indicam na literatura diversos autores.

BIBL IOGRAF JA CITADA

1. GILROY, D. \& MAYNE, J.E.D. The de-aeration of aqueous solutions. Journal of applied chemistry, London, 12:382, 1962.

2. KOLTHOFF, I.M. \& ELVIN, P.J. Treatise on analytical chemistry. S1; John Wiley and Sons, 1962, Part II, v.2. p. 122 e 139.

3. SPELLER, F.N. Film protection as a factor in corrosion. Tran sactions of the American Electrochemical Society, New York, $46: 225-40,1924$.

4. SEO, M. et alii. Auger analysis of the anodic oxide film on iron in neutral solutions. Corrosion Seience, oxford, 17:209-217,1977.

5. OGURA, K. Iron passivation in various buffer solutions. Journal of the Electroanalytical Chemistry, Lausame, 79:149-157, 1977.

6. NASCIMENTO, P.C. Contribuigão ao estudo da inibição da corrosão do aço ABNT-2006 em ägua contendo borato elou sizicato de só dio a temperatura ambiente. Dissertação de Mestrado. - UFRGSPPGEMM, Porto Alegre, 1987.

Recebido em dezembro, 1987; aceito em dezembro, 1987. 